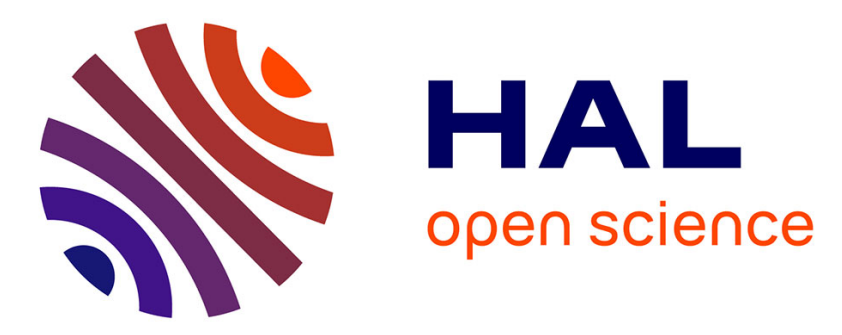

\title{
Declining uncertainty in transient climate response as CO2 forcing dominates future climate change
}

Gunnar Myhre, Olivier Boucher, Francois-Marie Breon, Piers Forster, Drew Shindell

\section{- To cite this version:}

Gunnar Myhre, Olivier Boucher, Francois-Marie Breon, Piers Forster, Drew Shindell. Declining uncertainty in transient climate response as $\mathrm{CO} 2$ forcing dominates future climate change. Nature Geoscience, 2015, 8 (3), pp.181 - 185. 10.1038/NGEO2371 . hal-01806251

\section{HAL Id: hal-01806251 https://hal.science/hal-01806251}

Submitted on 20 Aug 2021

HAL is a multi-disciplinary open access archive for the deposit and dissemination of scientific research documents, whether they are published or not. The documents may come from teaching and research institutions in France or abroad, or from public or private research centers.
L'archive ouverte pluridisciplinaire $\mathbf{H A L}$, est destinée au dépôt et à la diffusion de documents scientifiques de niveau recherche, publiés ou non, émanant des établissements d'enseignement et de recherche français ou étrangers, des laboratoires publics ou privés. 


\section{UNIVERSITY OF LEEDS}

This is a repository copy of Declining uncertainty in transient climate response as CO2 forcing dominates future climate change.

White Rose Research Online URL for this paper:

http://eprints.whiterose.ac.uk/85097/

Version: Accepted Version

\section{Article:}

Myhre, G, Boucher, O, Bréon, F-M et al. (2 more authors) (2015) Declining uncertainty in transient climate response as $\mathrm{CO} 2$ forcing dominates future climate change. Nature Geoscience, 8 (3). 181 - 185. ISSN 1752-0894

https://doi.org/10.1038/ngeo2371

\section{Reuse}

Unless indicated otherwise, fulltext items are protected by copyright with all rights reserved. The copyright exception in section 29 of the Copyright, Designs and Patents Act 1988 allows the making of a single copy solely for the purpose of non-commercial research or private study within the limits of fair dealing. The publisher or other rights-holder may allow further reproduction and re-use of this version - refer to the White Rose Research Online record for this item. Where records identify the publisher as the copyright holder, users can verify any specific terms of use on the publisher's website.

\section{Takedown}

If you consider content in White Rose Research Online to be in breach of UK law, please notify us by emailing eprints@whiterose.ac.uk including the URL of the record and the reason for the withdrawal request. 


\title{
Declining uncertainty in transient climate response as $\mathrm{CO}_{2}$ dominates future climate change
}

\author{
Gunnar Myhre ${ }^{1}$, Olivier Boucher ${ }^{2}$, François-Marie Bréon ${ }^{3}$, Piers Forster ${ }^{4}$, and Drew Shindell ${ }^{5}$ \\ ${ }^{1}$ Center for International Climate and Environmental Research - Oslo (CICERO), Oslo, Norway \\ ${ }^{2}$ Laboratoire de Météorologie Dynamique, Institut Pierre Simon Laplace, Centre National de la Recherche \\ Scientifique, Université Pierre et Marie Curie, 75252 Paris Cedex 05, France \\ ${ }^{3}$ Laboratoire des Sciences du Climat et de I'Environnement, IPSL, laboratoire CEA-CNRS-UVSQ, 91191 Gif sur \\ Yvette, France \\ ${ }^{4}$ School of Earth and Environment, University of Leeds, UK \\ ${ }^{5}$ Nicholas School of the Environment, Duke University, Durham, NC 27708, USA
}

Carbon dioxide $\left(\mathrm{CO}_{2}\right)$ has been the largest contributor to radiative forcing and surface temperature change over the industrial era but other anthropogenic drivers have had a significant role ${ }^{1,2}$. The large uncertainty in the total forcing makes it difficult to derive climate sensitivity from historical observations ${ }^{3-7}$. Based on data from Intergovernmental Panel of Climate Change (IPCC) reports, we show that the evolution of increased anthropogenic forcing and its reduced relative uncertainty between the Fourth and Fifth Assessment Reports ${ }^{1,8}$ can be expected to continue into the future, driven by the greater ease of reducing air pollution than $\mathrm{CO}_{2}$ emissions, long lifetime of $\mathrm{CO}_{2}$, and hence a stronger dominance of $\mathrm{CO}_{2}$ forcing. Here we present, using a statistical model, that the relative uncertainty in anthropogenic forcing of more than $40 \%$ quoted in the latest IPCC report for 2011 will be reduced by almost half by 2030, even without further improvement in scientific understanding. Absolute forcing uncertainty will also decline for the first time assuming projected decreases in aerosols occur. Other factors being equal, this stronger constraint on forcing will bring a significant reduction in the uncertainty of observation- 

expected by 2030.

Equilibrium climate sensitivity (ECS) and transient climate response (TCR) are two key measures that are used to evaluate how much the world might warm. TCR, which corresponds to the warming at the time of a doubling $\mathrm{CO}_{2}$ in a $1 \%$ - per-year $\mathrm{CO}_{2}$ increase scenario, is more policy-relevant than ECS to gauge the strength of climate change over coming decades. Although there is high confidence in the human contribution to climate change, current IPCC estimates of TCR show a large uncertainty range of 1.0 to $2.5^{\circ} \mathrm{C}(5-95 \%$ confidence interval $)$ for a doubling of $\mathrm{CO}_{2}\left(\right.$ ref. $^{2}$ ), which translates into an equivalent range of 0.27 to 0.68 $\left.{ }^{\circ} \mathrm{C}(\mathrm{W} \mathrm{m})^{-2}\right)^{-1}$ for the normalized definition of TCR that we adopt in this paper. Different methods and data sets have been used to derive estimates of TCR. Observation-based studies analyze the historical temperature record combined with information on the radiative forcing $(\mathrm{RF})^{5}$. The high uncertainty in historical RF is the main contributor to the uncertainty in the estimate of TCR and ECS through such methods ${ }^{4,6}$. Recent studies have shown that uncertainties in climate sensitivity will be reduced in the future based on longer available time series of surface temperature ${ }^{9}$. Here, we show that narrowing the uncertainty in RF can have a larger effect on the diagnosed TCR uncertainty.

Recently the IPCC $5^{\text {th }}$ Assessment Report assessed historical RF and its uncertainty ${ }^{1}$. In this paper we evaluate how uncertainty estimates have evolved between IPCC reports and estimate how we expect uncertainty estimates in RF to change in the future. We then evaluate the consequences of these trends on future uncertainty in diagnosing TCR from the available temperature observations record. 
Climate change can be driven by a wide range of emitted compounds as well as by physical and chemical processes ${ }^{1,8}$. The increase in well-mixed greenhouse gas abundances leads to a documented RF with small relative uncertainty $(\approx 10 \%)$ with all uncertainties presented here covering 5-95\% ranges and all relative uncertainties given as half the 5-95\% relative ranges unless otherwise stated. However, several of these greenhouse gases affect atmospheric chemistry leading to indirect effects that add to the RF uncertainty ${ }^{10-12}$. The positive RF from greenhouse gas increases since pre-industrial time has partly been counteracted by an overall negative RF by anthropogenic aerosols ${ }^{13-16}$; however the scattering and absorbing effects of atmospheric aerosols, including the component due to aerosol-cloud interactions, have uncertainties $^{17}$ that are much larger $(\sim 100 \%$ relative uncertainty $)$ than those associated with $\mathrm{CO}_{2}$ (see Supplementary Figure 1).

In the two most recent IPCC assessment reports (AR4 and AR5) best estimates for anthropogenic RF, together with their uncertainties, have been provided ${ }^{1,8}$. Similar estimates have been provided for earlier IPCC assessments ${ }^{18,19}$. The changes in RF estimates and their uncertainties between the reports are combinations of evolution in our scientific understanding and temporal change of the forcing agents between the RF evaluation years. Forcing estimates in the IPCC assessment are based on observations and modelling, and estimates constrained from observed climate change ${ }^{20,21}$ are ignored.

Relative to pre-industrial (1750) the total anthropogenic RF in AR5 (for year 2011) is larger than in AR4 (for year 2005) and TAR (for year 1998) and Figure 1 shows that further increases are expected under two extreme Representative Concentration Pathways (RCPs) for 2030 (see Methods). This increased total anthropogenic forcing from TAR and AR4 to AR5 is due to increases in greenhouse gases as well as increased scientific evidence for a less negative aerosol forcing ${ }^{1}$. In AR5 more aerosol processes are included in the forcing estimates 
(allowing for rapid adjustments in the atmosphere) relative to previous IPCC assessments, which resulted in a less negative RF estimate (-0.9 (-1.9 to -0.1$) \mathrm{W} \mathrm{m}^{-2}$ in AR5 versus $-1.2(-$ 2.4 to -0.6$) \mathrm{W} \mathrm{m}^{-2}$ ). Importantly, the relative uncertainty is reduced from TAR and AR4 to AR5 as shown in the right panel of Figure 1. Projections using the RCPs indicate that this reduction will continue and, by 2030 , the relative uncertainty in the total anthropogenic RF will be approximately halved relative to the latest IPCC assessments assuming no change in the scientific understanding of the forcing mechanisms (based on RCP2.6 and RCP8.5). Despite improvements in understanding, individual RF uncertainties changed relatively little between the assessment reports; yet the relative uncertainty in total RF has narrowed and can be expected to exhibit an even stronger decrease by 2030 .

The main cause of reduction in the relative uncertainty of the total RF is due to the increasing share of the $\mathrm{CO}_{2}$ contribution to the total as shown in Figure 2. In the last decades of the $20^{\text {th }}$ century, non- $\mathrm{CO}_{2}$ greenhouse gases made substantial contributions to the total, with rapid RF increases, while aerosols offset part of the greenhouse gas RF. The first decade in this century and projections for the next few decades show limited RF changes for non- $\mathrm{CO}_{2}$ greenhouse gases and a decrease in the offsetting negative aerosol forcing combined with an enhancement in the $\mathrm{CO}_{2} \mathrm{RF}$. This dramatic change in the relative RF contributions is due to fairly stable or declining recent and projected emissions of short-lived aerosols and aerosol precursors and most non- $\mathrm{CO}_{2}$ GHGs, in contrast with continuous increases in $\mathrm{CO}_{2}$ emissions ${ }^{22}$ coupled with its long lifetime. The forcing due to aerosols including their influence on clouds is better understood and quantified than in AR4, but uncertainties remain large ${ }^{17}$. Over the last two decades, there has been a large change in the distribution of aerosols, linked to reduced anthropogenic emissions in Europe and North America and increased emissions over South 
and East Asia. These opposite trends over the last decades are expected to more-or-less balance each other in terms of global mean $\mathrm{RF}^{1,23}$.

Figure 3 illustrates the time evolution of forcing used in this paper and its standard deviation. A maximum in the standard deviation (and hence absolute uncertainty) was reached around 2011 and is expected to decline further despite the increase in forcing. This leads to continued reduction in the relative uncertainty which, based on AR5 estimates, has been declining since about 1970 . Figure 3 clearly shows how the reduction in relative uncertainty is caused by the increasing dominance of $\mathrm{CO}_{2}$ in the total RF. Overall, the combination of enhanced $\mathrm{CO}_{2}$ forcing and weak magnitude of the non- $\mathrm{CO}_{2}$ and aerosols forcing both contributed to the recent reduction in uncertainty in anthropogenic forcing and likewise for the trend in the coming decades. Whereas the change in the relative uncertainty in the anthropogenic forcing from AR4 to AR5 is a combination of larger $\mathrm{CO}_{2}$ domination and improved quantification of the aerosol forcing, estimated further change by 2030 is solely due to a change in atmospheric abundances and no assumed change in scientific understanding about the individual drivers of climate change.

In the following we take the trends in anthropogenic RF estimates described above and examine their implications for estimating TCR from the historical record. TCR, when derived from historical observations or simulations relates the temperature change $(\Delta \mathrm{T})$ and the $\mathrm{RF}$ at a given time as follows:

$$
\mathrm{TCR}=\Delta \mathrm{T} / \mathrm{RF}
$$

The method used to estimate TCR here is similar to that used in recent studies ${ }^{6}$. Note that in the above equation TCR is expressed per unit of RF rather than for a doubling of $\mathrm{CO}_{2}$ abundance. It assumes quasi linear changes in $\Delta \mathrm{T}$ and $\mathrm{RF}$ over a chosen time period. Often 
TCR is assumed to be similar for all climate forcing mechanisms, although this may not be the $\operatorname{case}^{24}$ (see further discussion below and in the Supplementary Material). It may also depend on the rate of change of forcing ${ }^{25}$, which introduces a further small uncertainty term not accounted for here. The relative uncertainty in TCR (d TCR / TCR), where $d$ refers to half the uncertainty of the 5-95\% uncertainty range, is shown in Figure 4 a for RF relative uncertainties for AR4, AR5 and two RCPs for 2030 as a function of temperature change using the Monte Carlo simulations described and discussed in the Methods and Supplementary Material. Figure 4a shows that the relative uncertainty in TCR for the two RCPs is about half that found for AR5 data. The uncertainties related to temperature decrease as the temperature change increases, as can be seen for the two RCPs. However, the contribution from temperature uncertainties is less than $10 \%$ of the change in the relative uncertainty in TCR between AR5 and the RCPs for 2030, emphasizing that changes in the RF uncertainties are the dominant cause of the differences between AR5 and the RCPs for 2030.

The difference in RF uncertainty between AR4, AR5 and the two RCPs for 2030 translates into a large difference in the 5-95\% uncertainty range of the TCR for AR5 present-day temperature changes and best estimate RF as shown in the inset in Figure 4. The only difference in these ranges in TCR is caused by the declining uncertainty in RF. The better quantification of RF has the largest impact on the upper range of the derived TCR in absolute terms. Upper ranges of TCR are associated with low values of RF for which the lower bound of the aerosol RF is particularly relevant. A relatively symmetric distribution of RF leads to more asymmetric shape of the distribution of $\mathrm{TCR}^{7}$. The two RCPs uncertainty estimates in 2030 provide rather similar uncertainty ranges for TCR. The AR5 likely range of TCR can be reduced by about $50 \%$ based on climate data from two additional decades solely due to expected RF trends without further improvements in understanding (subject to continued 
availability of global surface temperature observations), see inset in Figure 4b. The absolute change in TCR is more dependent on temperature changes than the relative change in TCR. Figure $4 \mathrm{~b}$ shows that the absolute range in TCR will be at least $25 \%$ lower than the AR5 range over the RCP8.5 temperature ranges for 2030. For small temperature changes, the absolute uncertainty in TCR will see a greater reduction than the relative uncertainty in TCR between AR5 and the RCP for 2030 (up to 56\%).

Including an enhanced response to forcing in the Northern Hemisphere extratropics ${ }^{24}$ would increase the uncertainty in present-day TCR calculations, but would lead to an even greater narrowing of the TCR uncertainty moving to 2030 RCP conditions (see Supplementary Figure 2). The combination of air quality policies, the Montreal Protocol, trends in emission of climate related compounds, and most importantly the differentiated lifetime of the compounds suggests that the current evolution is likely to continue over the next few decades. Our findings illustrate that the stronger domination of $\mathrm{CO}_{2} \mathrm{RF}$ over the other forcing terms leads to a better quantification of TCR.

A better quantification of TCR will have a pronounced impact on the probability distribution of estimates of the amount of permissible $\mathrm{CO}_{2}$ emissions for a given temperature target, e.g the $2{ }^{\circ} \mathrm{C}$ target agreed to under the UNFCCC. Currently these emissions are highly uncertain ${ }^{26}$, but the expected $\mathrm{CO}_{2}$ domination will bring about (by itself) a better quantification of TCR and future projections of climate change.

\section{Methods}

All forcing values and their uncertainties used for figures and analysis are given in the IPCC AR5 in chapter text, supplementary or annex ${ }^{1,27}$, except for one case as described below for 
RCP2.6. The time evolution of historical and future RF is also from IPCC AR5. Projections for 2030 are based on the two most extreme RCPs, namely RCP2.6 and RCP8.5 ${ }^{28}$. These two RCP represent lower and upper projections over the next decades, respectively in terms of $\mathrm{CO}_{2}$ emissions and to some extent other climate relevant species. The development over the last decade is closest to RCP8.5 in terms of $\mathrm{CO}_{2}$ emissions. Other emission scenarios based on realistic development until 2030 have little impact on our findings. AR5 forcing estimates for aerosols and contrail induced cirrus include rapid adjustments and thus use the effective radiative forcing concept ${ }^{1,17}$, whereas in AR4 and previous IPCC reports rapid adjustments were not quantified. This makes some of the forcing estimates not entirely comparable, but allowing for the difference in treatment of rapid adjustment is the most consistent method for the aerosols between the IPCC reports. Forcing estimates for the two RCPs and AR5 are derived consistently with the same forcing concept and relative uncertainty for the individual drivers. The combined forcing from ozone and stratospheric water vapour in Figure 1 has a small change in the relative uncertainty between AR5 and the RCPs caused solely by abundance changes. The best estimate of the total anthropogenic RF for the various IPCC reports and the two RCPs is calculated based on the sum of the best estimate of each component. The range of the total anthropogenic RF is derived from the square root of the sum of the square of the upper and lower range deviation from the best estimate for the individual component. This allows for a consistent treatment of the best estimate and range, but may differ slightly from the report values in previous IPCC reports. The best estimate and uncertainty ranges for the two RCPs for 2030 are derived consistently with AR5 estimates, where the only change in estimate arise from atmospheric compositional change. Aerosols RF for RCP2.6 is not provided in the IPCC AR5 annex ${ }^{27}$ and is derived based on the difference in aerosol forcing from 2010 to 2030 as derived from one model (OsloCTM2) ${ }^{29}$ and thus also 
made consistent with the AR5 estimate. The main source of the time evolution of historical

194 and future forcing of aerosols and ozone for IPCC AR5 was a multi-model study ${ }^{30}$.

195 The time series of uncertainty used in Figure 3 are derived from a Monte-Carlo method, based

196 on converting IPCC AR5 uncertainty ranges in RF for 2011 into fractional error PDFs. We

197 then sample these to generate plausible RF time series.

198 For the calculations of changes in uncertainties in TCR probability distribution functions

199 (PDFs) of TCR from PDFs of temperature change and RF is derived using a Monte Carlo

200 random sampling approach. The values adopted to derive the PDFs are given in

201 Supplementary Table 1. Supplementary Figure 3 shows PDFs of TCR derived in this way

202 from PDFs of RF and temperature change. The 5-95\% interval is derived from the PDFs of

203 TCR.

204 Relative uncertainties are given as half the 5-95\% relative ranges. In Figure 4 the full 5-95\%

205 relative range is added to the relative uncertainty. In Figure 1 the relative uncertainties are 206 calculated as half the 5-95\% confidence range, divided by the best estimate. 
Figure 1: Anthropogenic forcing for four phases of IPCC reports and two RCPs. Aerosols, ozone and stratospheric water vapour, well-mixed greenhouse gases (WMGHG), land use change and total forcing are given for SAR (1750-1993), TAR (1750-1998), AR4 (17502005) and AR5 (1750-2011)) and two RCPs for 2030. . All the forcing values are based on best estimates reported in the IPCC reports, but with a consistent approach to calculate the total forcing which may differ slightly from reported values (see Methods). In SAR land use change was not estimated and thus not included in the total. Further, the RF of a given $\mathrm{CO}_{2}$ concentration was estimated to be $15 \%$ higher in SAR compared to the recent IPCC reports, adding $0.24 \mathrm{Wm}^{-2}$ to the total RF quoted in SAR. Estimate for AR5 and the two RCPs for 2030 includes rapid adjustments in the RF, whereas these have not been quantified earlier in SAR, TAR, and AR4. The probability density function for SAR and TAR are based on Boucher and Haywood ${ }^{19}$ and their simulation C1.5. The relative uncertainties are shown in the right panel. All uncertainty ranges correspond to 5-95\% confidence intervals with relative uncertainties given as half the 5-95\% relative range.

Figure 2: Decadal RF change between 1970 and 2010 and for 2020 to 2030 for two RCPs. The forcing is given for 1970 to 1980,1980 to 1990,1990 to 2000, and 2000 to 2010 and for 2020 to 2030 based on IPCC AR5 forcing values (see Methods). RF for ozone includes changes in the troposphere as well as in the stratosphere. Other WMGHG includes $\mathrm{CH}_{4}, \mathrm{~N}_{2} \mathrm{O}$ and halocarbons. All process associated with aerosol-radiation and aerosol-cloud interactions taken into account in the IPCC assessments are included for aerosol, except black carbon on snow. Consistent treatment is applied for RCPs for 2030 and AR5. Forcing mechanisms other than those shown in the figure are small (see Supplementary Information). 
233 Figure 3: Time evolution in RF and standard deviation in RF. RF for total anthropogenic, $\mathrm{CO}_{2}$, the combined non- $\mathrm{CO}_{2}$ greenhouse gases (GHG) such as $\mathrm{CH}_{4}, \mathrm{~N}_{2} \mathrm{O}$, halocarbons, ozone, and stratospheric water vapour, the others such as land use changes, black carbon on snow and ice, and contrails, and finally aerosols over the period 1850 and 2030 (a); the time evolution of the standard deviation of RF (b) and the ratio of the standard deviation of RF to the total RF (c). All the time evolutions of forcing are taken from IPCC AR5 (see Methods). RCP8.5 and RCP2.6 are shown with solid and dashed lines, respectively.

Figure 4: The relative a) and absolute b) uncertainty in TCR for the indicated conditions as a function of temperature change. The results are based on Monte Carlo simulations of the PDF of TCR as a function of temperature change and relative uncertainty in RF for AR4, AR5, and RCP2.6 and RCP8.5 for 2030 (see methods for source of RF values). The uncertainties in RF for the two RCPs are based on the scientific knowledge in AR5 and projected abundance changes. Observed temperature changes and their uncertainties from AR4 and AR5 are adopted in the calculations of the relative uncertainty in TCR, whereas for RCP2.6 and RCP8.5 results are shown for CMIP5 simulated temperature changes. The absolute uncertainty in temperature change for 2030 is assumed to be same as in AR5. The relative uncertainties and best estimates of TCR are shown as horizontal lines with ranges shown for lower and upper bound of the relative uncertainty in TCR and TCR (lines for AR4 and AR5 whereas bands for the two RCPs for 2030). The inset shows the TCR and the uncertainty range from Equation 1 for temperature changes and RF at the time of AR5 but with different relative uncertainty in RF from AR4, AR5, and RCP2.6 and RCP8.5 for 2030. The diamond symbol shows the TCR with the best estimate RF and is thus constant to illustrate solely the difference in relative uncertainty in RF. 
Myhre, G. et al., Anthropogenic and Natural Radiative Forcing, in Climate Change 2013: The Physical Science Basis. Contribution of Working Group I to the Fifth Assessment Report of the Intergovernmental Panel on Climate Change, edited by T. F. Stocker et al. (Cambridge University Press, Cambridge, United Kingdom and New York, NY, USA, 2013), pp. 659-740. Stocker, T. F., D. Qin, G.-K. Plattner, M. Tignor, S. K. Allen, J. Boschung, A. Nauels, Y. Xia, V. Bex and P. M. Midgley ed., IPCC, 2013: Summary for Policymakers. (Cambridge University Press, Cambridge, United Kingdom and New York, NY, USA, 2013).

Aldrin, M. et al., Bayesian estimation of climate sensitivity based on a simple climate model fitted to observations of hemispheric temperatures and global ocean heat content. Environmetrics 23, 253-271 (2012).

Andreae, M. O., Jones, C. D., and Cox, P. M., Strong present-day aerosol cooling implies a hot future. Nature 435, 1187-1190 (2005).

Knutti, R. and Hegerl, G. C., The equilibrium sensitivity of the Earth's temperature to radiation changes. Nature Geoscience 1, 735-743 (2008).

Otto, A. et al., Energy budget constraints on climate response. Nature Geoscience 6, 415-416 (2013).

Roe, G. H. and Armour, K. C., How sensitive is climate sensitivity? Geophysical Research Letters 38, L14708 (2011).

Forster, P. et al., Changes in Atmospheric Constituents and in Radiative Forcing, in Climate Change 2007: The Physical Science Basis. Contribution of Working Group I to the Fourth Assessment Report of the Intergovernmental Panel on Climate Change (Cambridge University Press, Cambridge, United Kingdom and New York, NY, USA, 2007).

Urban, N. M. et al., Historical and future learning about climate sensitivity. Geophysical Research Letters 41, 2543-2552 (2014). Isaksen, I. S. A. et al., Atmospheric composition change: Climate-Chemistry interactions. Atmospheric Environment 43, 5138-5192 (2009).

Raes, F., Liao, H., Chen, W. T., and Seinfeld, J. H., Atmospheric chemistry-climate feedbacks. Journal of Geophysical Research-Atmospheres 115 (2010).

Shindell, D. T. et al., Improved Attribution of Climate Forcing to Emissions. Science 326, 716718 (2009).

Crook, J. A. and Forster, P. M., A balance between radiative forcing and climate feedback in the modeled 20th century temperature response. Journal of Geophysical ResearchAtmospheres 116, D17108 (2011).

Huber, M. and Knutti, R., Anthropogenic and natural warming inferred from changes in Earth's energy balance. Nature Geoscience 5, 31-36 (2012).

Hansen, J., Sato, M., Kharecha, P., and von Schuckmann, K., Earth's energy imbalance and implications. Atmospheric Chemistry and Physics 11, 13421-13449 (2011).

Ramanathan, V., Crutzen, P. J., Kiehl, J. T., and Rosenfeld, D., Atmosphere - Aerosols, climate, and the hydrological cycle. Science 294, 2119-2124 (2001).

Boucher, O. et al., Clouds and Aerosols, in Climate Change 2013: The Physical Science Basis. Contribution of Working Group I to the Fifth Assessment Report of the Intergovernmental Panel on Climate Change, edited by T. F. Stocker et al. (Cambridge University Press, Cambridge, United Kingdom and New York, NY, USA, 2013), pp. 571-657. Haywood, J. and Schulz, M., Causes of the reduction in uncertainty in the anthropogenic radiative forcing of climate between IPCC (2001) and IPCC (2007). Geophysical Research Letters 34 (2007).

Boucher, O. and Haywood, J., On summing the components of radiative forcing of climate change. Climate Dynamics 18, 297-302 (2001). 
Forest, C. E. et al., Quantifying uncertainties in climate system properties with the use of recent climate observations. Science 295, 113-117 (2002). future climate change from observations and climate model ensembles. Nature 416, 719-723 (2002). Peters, G. P. et al., COMMENTARY: The challenge to keep global warming below 2 degrees C. Nature Climate Change 3, 4-6 (2013). Murphy, D. M., Little net clear-sky radiative forcing from recent regional redistribution of aerosols. Nature Geoscience 6, 258-262 (2013). Shindell, D. T., Inhomogeneous forcing and transient climate sensitivity. Nature Climate Change 4, 274-277 (2014).

25 Forster, P. M. et al., Evaluating adjusted forcing and model spread for historical and future scenarios in the CMIP5 generation of climate models. Journal of Geophysical ResearchAtmospheres 118, 1139-1150 (2013).

Meinshausen, M. et al., Greenhouse-gas emission targets for limiting global warming to 2 degrees C. Nature 458, 1158-1162 (2009). 2013: The Physical Science Basis. Contribution of Working Group I to the Fifth Assessment Report of the Intergovernmental Panel on Climate Change, edited by T. F. Stocker et al. (Cambridge University Press, Cambridge, United Kingdom and New York, NY, USA, 2013), pp. 1395-1445. Change 109, 5-31 (2011).

Skeie, R. B. et al., Anthropogenic radiative forcing time series from pre-industrial times until 2010. Atmospheric Chemistry and Physics 11, 11827-11857 (2011). Shindell, D. T. et al., Radiative forcing in the ACCMIP historical and future climate simulations. Atmospheric Chemistry and Physics 13, 2939-2974 (2013). 
341 Correspondence and requests for material should be addressed to GM

342 (gunnar.myhre@cicero.oslo.no)

343

344 Acknowledgements

345 GM was supported from the Norwegian Research Council project SLAC (208277)

346

347 Author contributions

348 GM, FMB, DS initiated the study with additional contribution on the design on the study from 349 PF and OB. GM, OB, FMB, PF, and DS performed the analysis and wrote the paper.

350 
Aerosols $\quad \mathrm{O}_{3}+\mathrm{H}_{2} \mathrm{O}^{\text {Strat }} \quad$ WMGHG

\section{Land Use Total Anthropogenic}

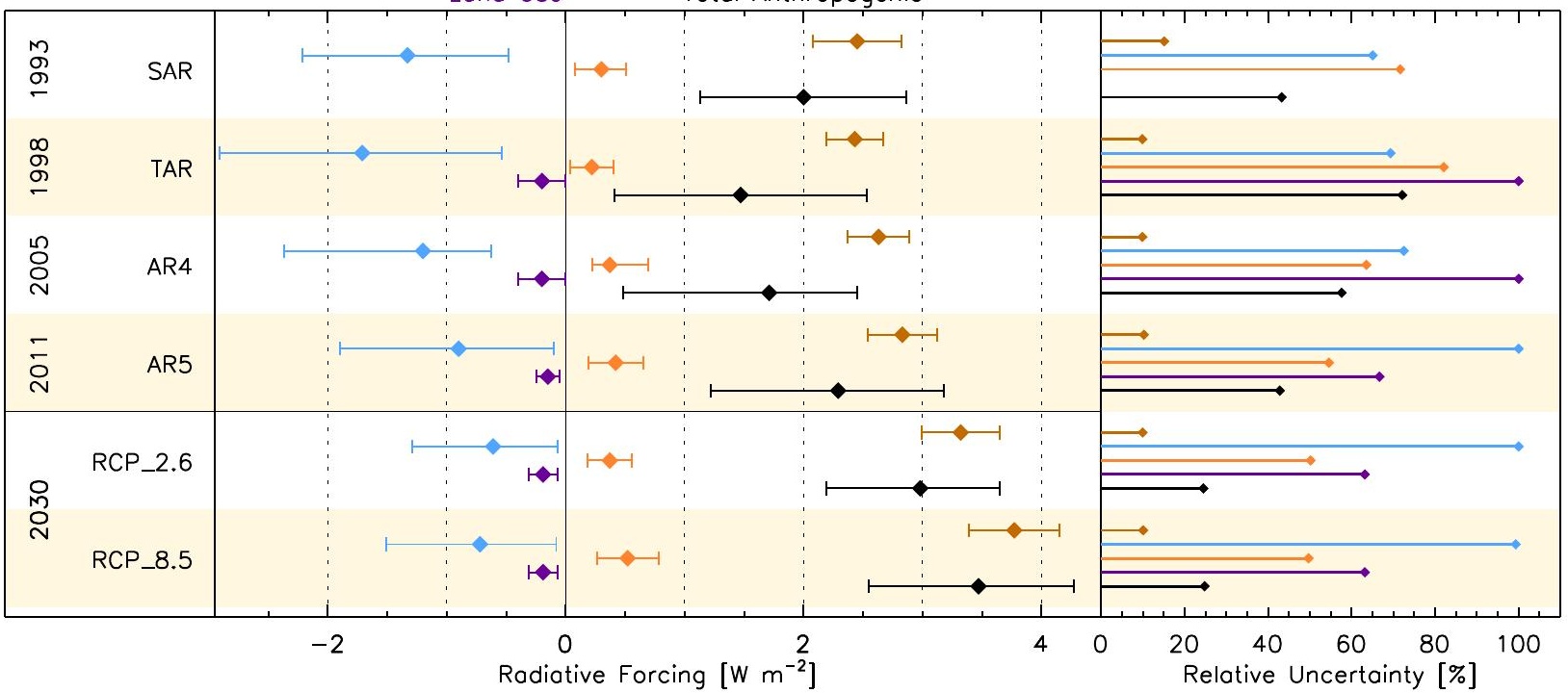




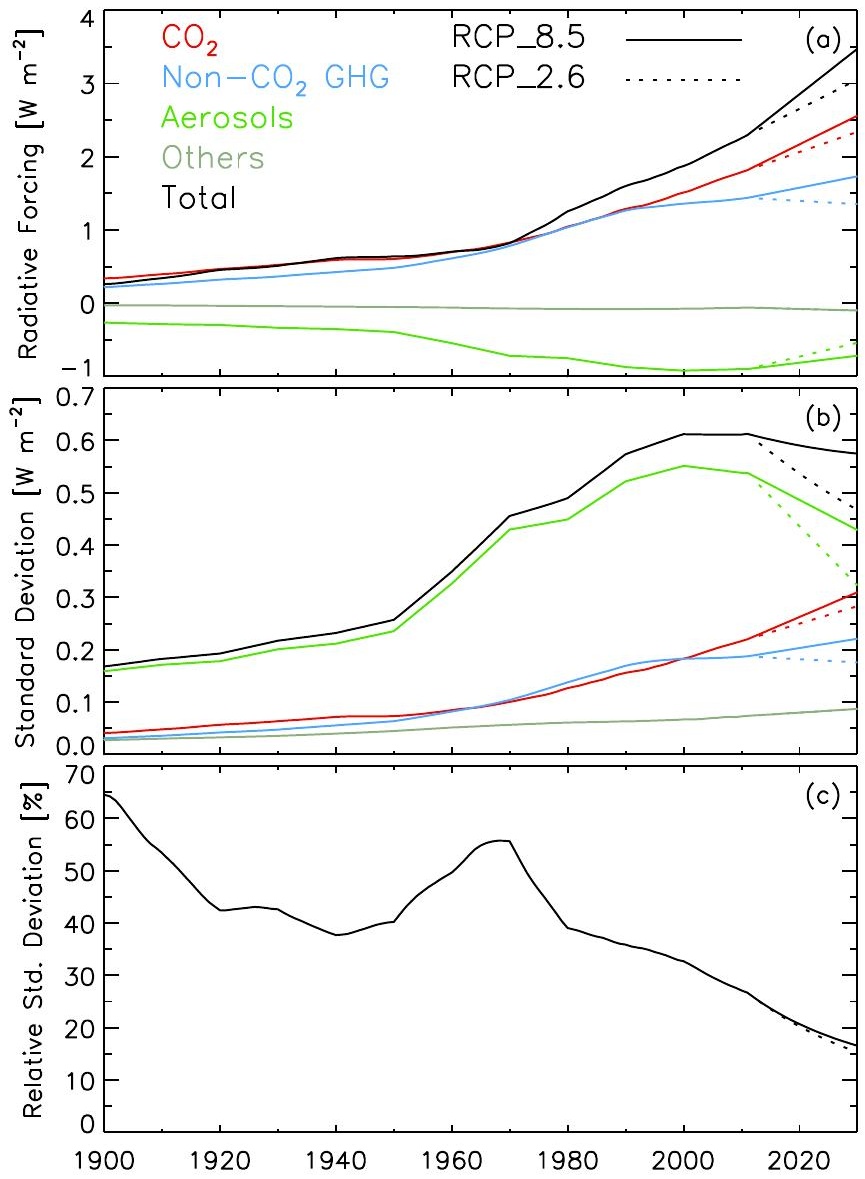


